\title{
Introduction to the January 2021 Issue
}

\section{Charles B. Hodges ${ }^{1}$}

Accepted: 9 December 2020 / Published online: 15 January 2021

(C) Association for Educational Communications \& Technology 2021

We are starting a new year. I have hope that it will be better than 2021 in many ways! This issue of the TechTrends starts the 65 volume for the journal and I always hope that a new volume will in some way be better than the last. The issue includes some of our regular columns, like ICT International, The History Corner, and Book Reviews. Rethinking Technology \& Creativity in the twenty-first Century is now the column, Reimagining Technology, Creativity \& Learning. It also includes 10 original papers.

The original papers begin with a description of CAFE, a simple instructional design model to assist K-12 teachers as they move to remote teaching. Next, a team led by Brendan Calandra provides computer science learning outcomes from an NSF-funded project in which middle school students used MIT's App Inventor to design, create, and remix mobile apps during an afterschool program. Mobile apps also are the topic of the next paper by Hsu, Ching, Callahan, and Bullock as they share their work enhancing STEM majors' college trigonometry learning through collaborative mobile apps coding. Georgiou and Ioannou are up next, with their paper presenting a large-scale study on the implementation and systematic evaluation of a learning experience design, developed and enacted by a cohort of eight primary education teachers to support their students' engagement and learning in mathematics. The purpose of the next paper, by Chapman and Marich, is to report a case study of two teachers who use the social media platform Twitter with their students to teach civic knowledge and skills. The purpose of the next paper, by Alamri, Watson, and Watson, is to provide an overview of personalized learning theory, learning technology that supports the personalization of higher education, current practices, as well as case studies of implementing technology models to support personalized learning. Moon, Francom, and Wold explore learning from versus learning with technology in the next paper. Following Moon, Francom, and Wold are Csikar and Stefaniak with their examination of the use of heuristics in adaptive narratives to inform decision-making practices. Decision-making also is the topic of the next paper in which Giblin and Stefaniak examinine decision-making processes and heuristics in academic help-seeking and instructional environments. The final paper in the issue, by Francom and collaborators, reports their comparison of Google Classroom and D2L Brightspace using the technology acceptance model.

As always, if you are interested in submitting a manuscript to TechTrends, or if you want to be a reviewer, please contact me. Encourage your colleagues to submit their work to TechTrends, to read TechTrends, and to consider joining AECT! If you have a question about the journal, my phone number is $912-478-0497$ and my email address is chodges@georgiasouthern.edu. Email is the best way to reach me. Also, you can follow TechTrends on Twitter: @ AECTTechTrends.

Publisher's Note Springer Nature remains neutral with regard to jurisdictional claims in published maps and institutional affiliations.

Charles B. Hodges

chodges@georgiasouthern.edu

1 Georgia Southern University, Statesboro, GA, USA 